\title{
Relative Contribution of Different Source Categories to Ozone Exceedances in the Houston-Galveston-Brazoria Area
}

\author{
Raghava R. Kommalapati ${ }^{1,2}$, Md Tarkik Shahriar ${ }^{1,2}$, Venkata S. V. Botlaguduru1, Hongbo Du1, \\ Ziaul Huque ${ }^{1,3}$ \\ ${ }^{1}$ Center for Energy \& Environmental Sustainability, Prairie View A \& M University, Prairie View, USA \\ ${ }^{2}$ Department of Civil \& Environmental Engineering, Prairie View A \& M University, Prairie View, USA \\ ${ }^{3}$ Department of Mechanical Engineering, Prairie View A \& M University, Prairie View, USA \\ Email: ^rrkommalapati@pvamu.edu, tarkikshahriar@gmail.com, vsbotlaguduru@pvamu.edu,hodu@pvamu.edu, \\ zihuque@pvamu.edu
}

How to cite this paper: Kommalapati, R.R., Shahriar, Md.T., Botlaguduru, V.S.V., $\mathrm{Du}, \mathrm{H}$. and Huque, Z. (2018) Relative Contribution of Different Source Categories to Ozone Exceedances in the Houston-Galveston-Brazoria Area. Journal of Environmental Protection, 9, 847-858. https://doi.org/10.4236/jep.2018.98052

Received: June 14, 2018

Accepted: July 24, 2018

Published: July 27, 2018

Copyright () 2018 by authors and Scientific Research Publishing Inc. This work is licensed under the Creative Commons Attribution International License (CC BY 4.0).

http://creativecommons.org/licenses/by/4.0/

\section{(c) (i) Open Access}

\begin{abstract}
The goal of this study is to analyze the relative contribution of different emission source categories to ozone in the Houston-Galveston-Brazoria (HGB) area of Texas. Emission Processing System (EPS3) is used to prepare the emission files for five different source combination cases (Base case, Biogenic, Area + Biogenic, Mobile + Biogenic, Low-level Point + Biogenic). These emission files are used to perform photochemical modeling with Comprehensive Air Quality Model with Extensions (CAMx), and the results are analyzed with Visual Environment for Rich Data Interpretation (VERDI) tool. The daily maximum ozone concentrations and individual contributions of the source categories were analyzed over a 15-day study period between June 1-15, 2012, at three locations (University of Houston-Sugarland, Bayland Park and Conroe). Biogenic sources contributed an average of $49.7 \% \pm$ $12.8 \%, 43.1 \% \pm 12.0 \%$, and $39.9 \% \pm 9.28 \%$ at Sugarland, Bayland Park and Conroe sites respectively, indicating the significance of isoprene emissions from the vegetation in northeast Houston. On peak ozone days, contribution of Mobile + Biogenic source category averages about $80.1 \% \pm 12.6 \%$, $79.9 \% \pm 6.50 \%$, and $75.9 \% \pm 10.9 \%$ at Sugarland, Bayland Park and Conroe sites respectively, indicating the dominance of mobile source $\mathrm{NO}_{\mathrm{x}}$ emissions and the necessity for regulatory focus on mobile source emissions control.
\end{abstract}

\section{Keywords}

Ozone, Houston, CAMx, Biogenic, Mobile Sources 


\section{Introduction}

On April 30, 2004, the Houston-Galveston-Brazoria (HGB) area comprising eight counties in Texas, was designated as a "moderate nonattainment" area under the 1997 8-hour ozone NAAQS. Subsequent re-classifications include changes to "severe nonattainment area" status, effective October 31, 2008, "marginal" status effective July 20, 2012 and "moderate" status on December 14, 2016 for the 2008 8-hour ozone NAAQS. For the newly assigned moderate nonattainment status, July, 2018 was set as the deadline to demonstrate attainment [1]. Ozone formation in the HGB area is associated with emissions from on- and off-road vehicles, power plants and biogenic sources. However, the extensive petrochemical industry that contributes both reactive VOCs and $\mathrm{NO}_{\mathrm{x}}$ to the pollutant mix and ozone formation, makes it a unique region [2]. HGB area experiences hot and humid summer periods with intense solar radiation [3]. Through favorable emissions conditions, ozone levels in this area are known to be enhanced under suitable meteorological conditions [2] [4]. In a number of previous studies, rapid ozone production has been observed, facilitated by highly reactive volatile organic compounds (HRVOCs) and nitrogen oxides $\left(\mathrm{NO}_{\mathrm{x}}\right)$ [2] [5] [6]. Many of the petrochemical facilities around the Ship Channel area have been observed to play a significant role in determining the occurrence of ozone exceedances [3]. August and September months are the most susceptible times of the year for ozone exceedance, due to the existence of favorable meteorological conditions [7]. High temperatures, abundant sunshine, weak local winds and higher frequency of winds from the north during September play major role in increasing the background ozone [8]. One of the distinctive factors to rapid ozone formation in the HGB area is the releases of HRVOCs from industrial sources [9]. From the previous studies by Kleinman et al. (2003), it has been observed that the rate of ozone formation can be up to $200 \mathrm{ppb} / \mathrm{h}$, in contrast to 40 $\mathrm{ppb} / \mathrm{h}$, which is the maximum in the other urban areas [2] [10]. In 2000, Texas Air Quality Study observational data have been collected, which indicated that the rapid and efficient ozone formation originated mostly from the high petrochemical industrial emissions [2] [6]. It has also been indicated by these data that the plumes occurring rapid and efficient ozone formation contained high concentration of light olefins (especially butenes (butylenes), propene (propylene), ethane (ethylene), and 1,3-butadiene), which by the State of Texas have been designated as highly reactive volatile organic compounds (HRVOCs) [9].

Li et al. (2007) comprehensively investigated the impacts of biogenic emissions on photochemical ozone production in the Houston area [11]. The simulated concentrations of total reactive nitrogen $\left(\mathrm{NO}_{\mathrm{y}}\right)$ and the variations of peroxyacetyl nitrate (PAN) from the chemical transport model (CTM) were in agreement with the monitored observations. Reasonable comparison between available observations and CTM simulations has also been identified despite the uncertainties that existed in the case of isoprene emissions and meteorological inputs. Ozone plume was observed to occur in the urban Houston area in the af- 
ternoon, with isoprene emissions playing a major role accounting for approximately $20-40 \mathrm{ppb}$ of ozone concentrations in the HGB area. Compared to the urban Houston area, relatively higher ratios of $\mathrm{VOC} / \mathrm{NO}_{2}$ reactivity were measured in the Houston Ship Channel. Washenfelder et al. (2010) characterized $\mathrm{NO}_{\mathrm{x}}, \mathrm{SO}_{2}$, ethene, and propene from industrial emission sources in the Houston area by examining the trends of emissions from industrial sources between 2000 and 2006 [12]. Through the use of relative $\mathrm{OH}$ radical reactivity, the HRVOCs were additionally identified. The use of abatement controls at industrial facilities provided a reduction of $29 \% \pm 20 \%$ (mean \pm standard deviation) in $\mathrm{NO}_{\mathrm{x}}$ emissions between 2000 and 2006. A reduction of $30 \% \pm 30 \%$ in emissions of alkenes (ethene, propene) was also observed during the same period. The study noted the Houston Ship Channel to be the largest source among the many other petrochemical industrial areas (Texas City, Chocolate Bayou, Sweeny, and Freeport) examined [12].

A review of the literature found limitation of studies primarily focused on analyzing the ozone exceedances in the HGB area due to different source categories. Individual studies have been performed concentrating on high level of ozone concentrations due to different industrial sources (petrochemical industries, electricity generation facilities), biogenic sources, effects of different meteorological parameters, as well as local and regional transport of ozone [13]. There exists a considerable gap in the literature regarding contribution of different source categories on the high level of ozone concentrations in the HGB area. This study would be an attempt to fill the gap and thus identify the source category that is mostly responsible for ozone exceedances in the HGB area. The individual contribution of different source categories will be obtained by performing photochemical model simulations with Comprehensive Air Quality Model with Extensions (CAMx).

\section{Methodology}

The primary goal of this study is to analyze the impacts of different source categories on the ozone exceedance in the HGB area. Ozone concentrations at a particular location depend on a number of variables such as quantity of emissions, types of source categories, meteorology, and land use. In this study, a module of Emissions Processing System (EPS3) was used to prepare the emission files for five different cases (Base case, Biogenic, Area + Biogenic, Mobile + Biogenic, Low-level Point + Biogenic) based on four different source categories (Biogenic, Low-level Point, Mobile, and Area sources). Three of these emission sources are anthropogenic (Mobile source, point source, and area source) and one is Biogenic source. These emission files along with other input files have been utilized to perform photochemical model simulations at three sites located in the HGB area. The details on the sites selected are described in Table 1 and Figure 1. Sites 1 and 2 are the locations where actual air quality monitoring is conducted by the Environmental Protection Agency (EPA) and the Texas Commission on Environmental Quality (TCEQ), and are situated where public exposure to ozone is 


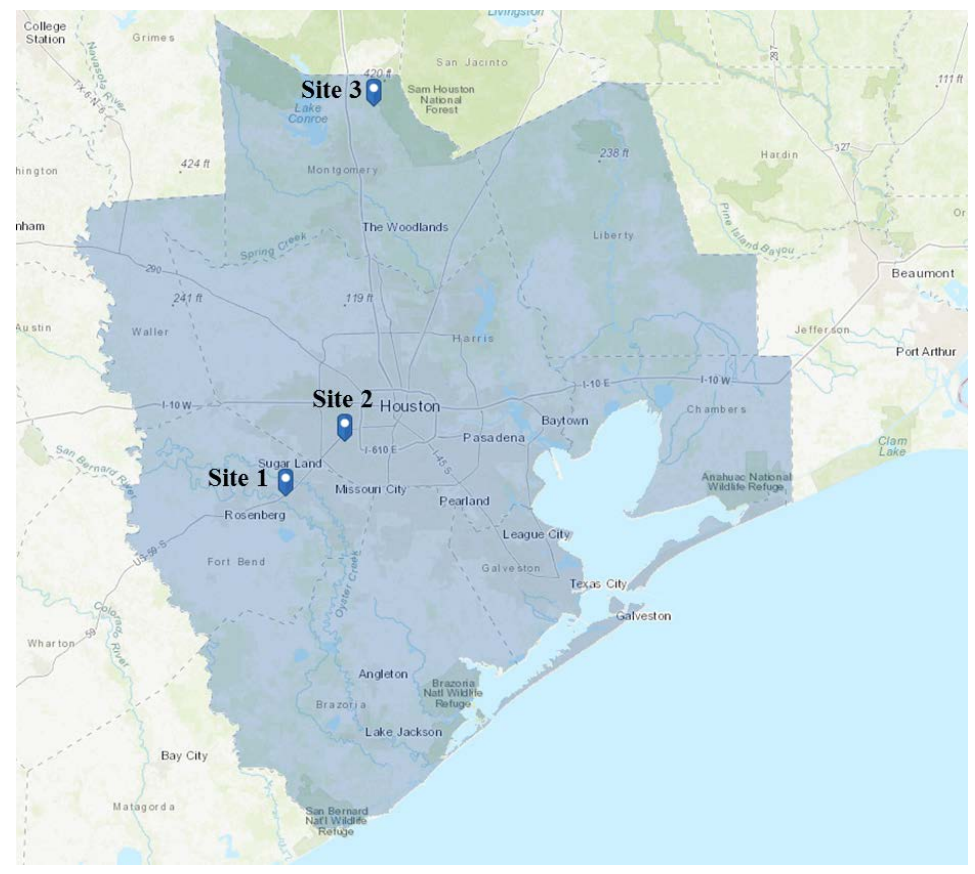

Figure 1. Map of the HGB nonattainment area with three sites selected for current study [14].

Table 1. Site Information for CAMx analysis.

\begin{tabular}{cccc}
\hline Site & Location & Latitude & Longitude \\
\hline Site 1 & University of Houston-Sugarland & N29 $34^{\prime} 27^{\prime \prime}$ & W95 $38^{\prime} 59^{\prime \prime}$ \\
Site 2 & Bayland Park & N29 $41^{\prime} 45^{\prime \prime}$ & W95 $29^{\prime} 57^{\prime \prime}$ \\
Site 3 & Conroe & N30 $26^{\prime} 13^{\prime \prime}$ & W95 $25^{\prime} 29^{\prime \prime}$ \\
\hline
\end{tabular}

high [14]. Site 3 is located near Conroe in the northwest region of the HGB area, and away from downtown Houston. From the CAMx results, ozone concentrations were analyzed using the VERDI software. Analysis has been performed based on the daily maximum concentrations of ozone over the 15 days corresponding to the June 1-15, 2012 episode. A comparison with Base case (all sources) is included in which all types of emission sources are considered.

All the input files necessary for performing photochemical modeling with CAMx were accessed from TCEQ's public access support site [15]. EPS3 was used to prepare the emission files and photochemical model simulations have been performed using CAMx 6.1 version. In order to generate temporally resolved, spatially distributed and speciated model-ready emission files which can be directly used in CAMx, MRGUAM (MeRGeUAMfiles) module of the EPS3 software has been used. MRGUAM module which includes in the EPS3 core system is capable of merging multiple emissions files into one file for modeling purpose. It is used to combine the low-level emissions data from virtually any number of CAMx-format files into a single file. This module has been used to merge the biogenic source emission file with the mobile source emission file 
(Mobile + Biogenic), low-level point source file (Point + Biogenic), and area source file (Area + Biogenic). In order to generate the emission files of Mobile + Biogenic, three emission source files (onroad, nonroad, and offroad) were merged together with the Biogenic emission source files [15]. However, for the cases of Basecase and Biogenic, the emission files were directly used from the available data uploaded by TCEQ [15]. From the output of MRGUAM module the binary files have been generated which were directly used as the emission file input in CAMx. In addition to the merged CAMx emissions file, message files containing tabular emissions totals have also been produced for each of the simulation date. The next stage in the methodology includes photochemical model simulations with CAMx using the already developed emission files with EPS3 module (MRGUAM). However, a number of other inputs are required by CAMx to perform the simulations such as the files that define the chemical mechanism and describe the photochemical conditions, surface characteristics, initial/boundary conditions, emission rates, and various meteorological fields over the entire modeling domain. In this particular study, 6.1 version of CAMX has been used which uses chemistry mechanism 6. In this version, 67 gas species are chemically analyzed through 156 chemical reactions. Additionally, the number of primary photolysis reactions is 152 and the number of secondary photolysis reaction is four. Visual Environment for Rich Data Interpretation (VERDI) tool is used to visualize the results of CAMx. Although in CAMx the output is given for all the three types of grid sizes $(36 \mathrm{~km} \times 36 \mathrm{~km}, 12 \mathrm{~km} \times 12 \mathrm{~km}, 4 \mathrm{~km} \times 4$ $\mathrm{km}$ ) but for the purpose of visualizing the pollutant concentration in the HGB area only the output for TX_4 $\mathrm{km}$ has been used in the VERDI interface.

\section{Results and Discussion}

From the CAMx results of ozone concentrations for the 3 sites, diurnal variations of base case ozone concentrations have been plotted for 15 days in Figure 2. It can be observed from the figure that during the 15 days of ozone study, Sites 1 and 2 located in the urban area have consistently higher concentrations during June 1-8, compared to the Site 3 near Conroe. The results also show that during this period, the highest ozone concentrations occurred on Friday, June $1^{\text {st }}$, Thursday June $7^{\text {th }}$ and Sunday, June $9^{\text {th }}$ for Sites 1 and 2. For Site 3, the peak ozone days tend to be spread out on Saturday June $2^{\text {nd }}$, Monday June $4^{\text {th }}$, Sunday June $10^{\text {th }}$ and Wednesday June $13^{\text {th }}$. This spreading out of peak ozone indicated the weakening of "weekend effect" at Site 3. The "weekend effect" of ozone can be defined as a phenomenon when the peak ambient concentrations of ozone on the weekends (Saturdays and Sundays) are observed to be higher than that of weekdays [16]. The higher ozone concentrations during weekends in comparison to weekdays typically occur as a result of the higher vehicular traffic normally observed on the weekdays. The remote location of Site 3, and limited time period of this study can be attributed to the weakening of this phenomenon in these results. The conversion of $\mathrm{NO}$ (from vehicular exhaust) to $\mathrm{NO}_{2}$ is a slow 


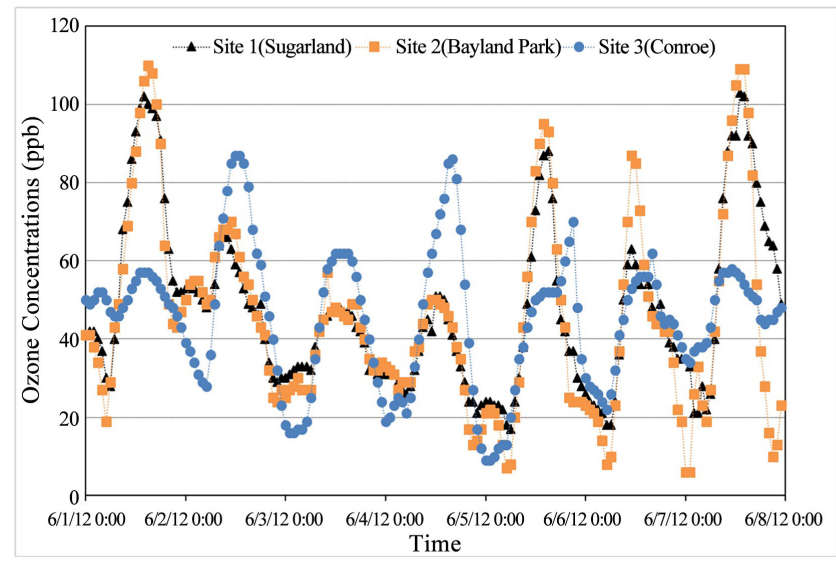

(a)

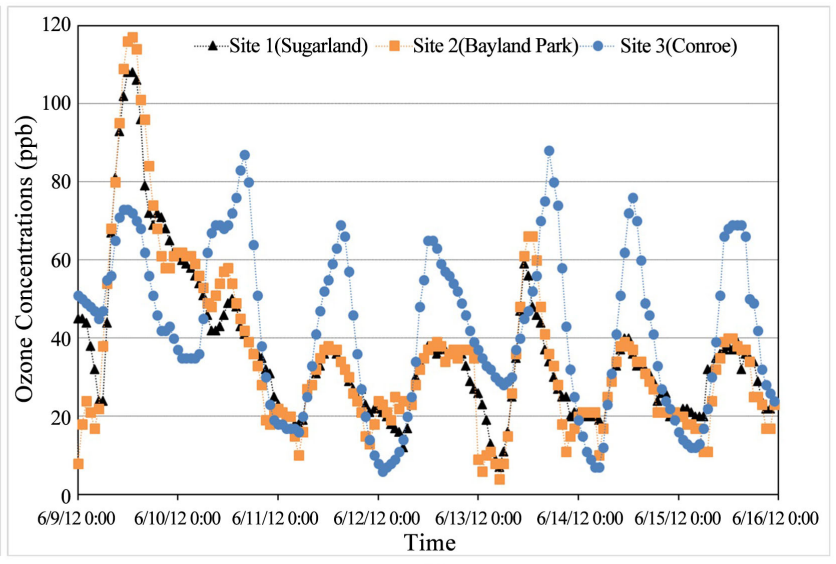

(b)

Figure 2. Diurnal variations in base case ozone concentrations at the three sites, Site 1 (Sugarland), Site 2(Bayland Park), Site 3 (Conroe), (a) June 1-8, 2012; (b) June 9-15, 2012.

process that facilitates ozone formation. The conversion of $\mathrm{NO}_{2}$ to $\mathrm{NO}$ is a faster process and this NO destroys some portion of ozone that is already formed [17]. For the weekends, the peak values of maximum daily ozone was observed to be 117, 108 and $87 \mathrm{ppb}$ at Sites 1 (Sugarland), 2 (Bayland Park), and 3 (Conroe) respectively, close to exceeding the 1-hr ozone NAAQS of $120 \mathrm{ppb}$. It is also well evident from Figure 2, that geographical location within the Houston metro area, and proximity to vehicular traffic significantly influences peak ozone levels. Diesel engines and highway gasoline vehicles might have contributed most towards this peak ozone at Bayland Park [18].

The diurnal variations in ozone under the five emission source categories, at Conroe site are presented in Figure 3, and the analysis of these variations for different cases indicates that during the daytime (12:00 PM and 6:00 PM) other than Base case, Mobile + Bio has been observed to produce highest concentrations of ozone. The results also indicate that during the nighttime between 12:00 am and 6:00 AM, the ozone concentrations were highest for Point + Bio case. This phenomenon has distinctively been observed for June $2^{\text {nd }}-6^{\text {th }}, 9^{\text {th }}-12^{\text {th }}$, and $14^{\text {th }}-15^{\text {th }}$. Between $12 \mathrm{AM}$ and $6 \mathrm{AM}$ on $3^{\text {rd }}$ June, very low level of ozone concentrations can be observed for the case of Mobile + Bio and major source category is the point sources ( $\mathrm{LPt}+\mathrm{Bio})$. This could be explained by the fact that some of the facilities considered as the point sources, refineries and petrochemical facilities, are operated throughout the $24-\mathrm{hr}$ period. Although during the daytime they are not the highest contributing sources of ozone, during the nighttime the continuous emissions of ozone precursors from these facilities might have contributed to sustained transport from the ship channel. However, during the nighttime the ozone concentrations are significantly lower than the daytime because of the absence of sunlight and major temperature drop. During the nighttime, a significant drop of vehicular activities can be observed, which possess a major portion of mobile sources. Consequently, the emission of ozone precursors from these large numbers of sources is also absent which might have 

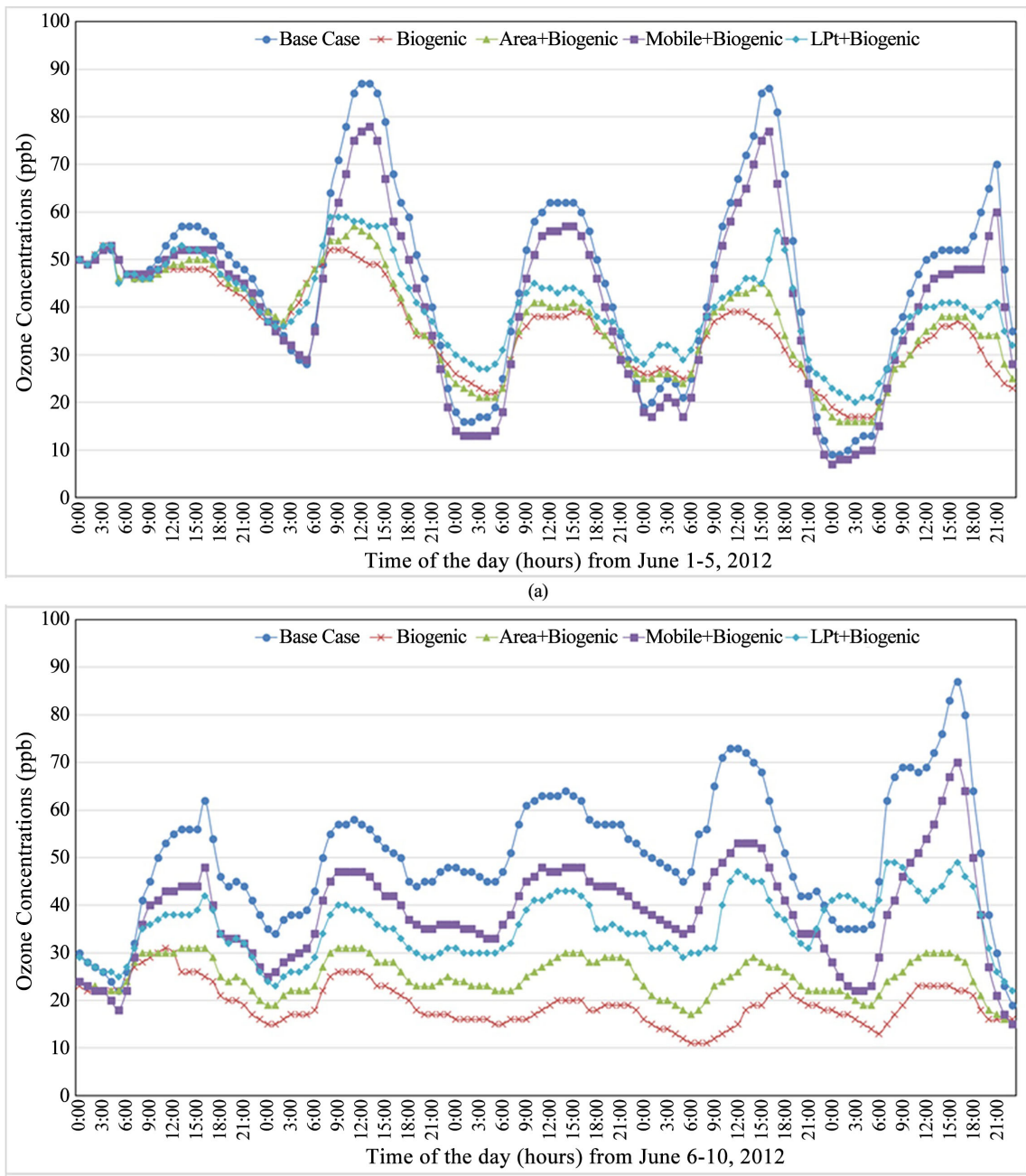

(b)

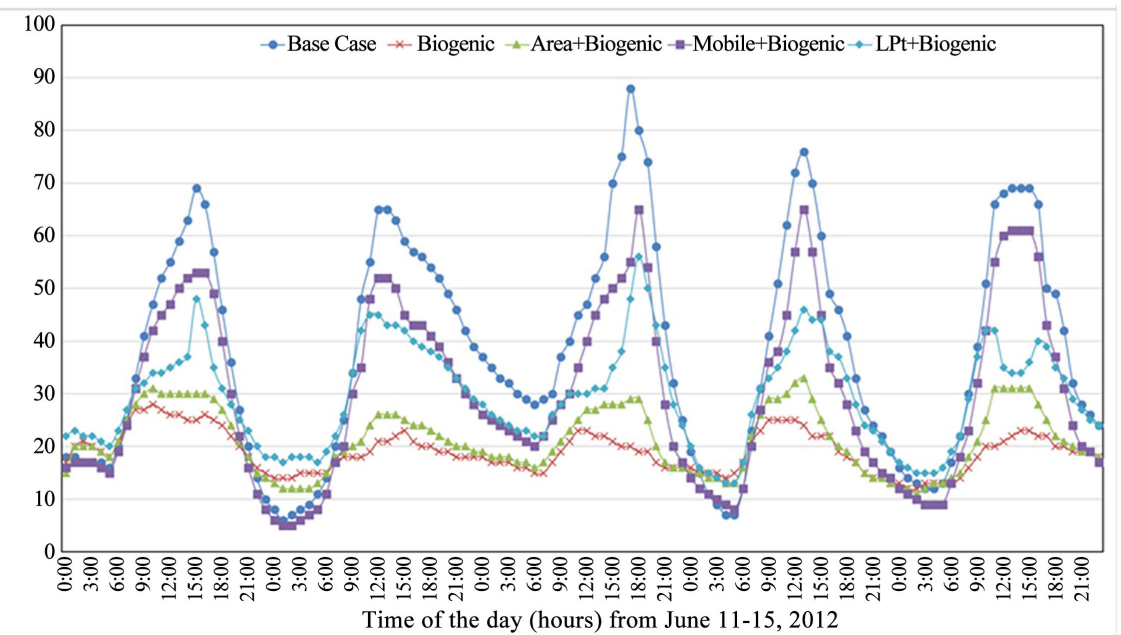

(c)

Figure 3. Diurnal variations in ozone concentrations due to different source categories at the Site 3 (Conroe), (a) June 1-5, 2012; (b) June 6-10, 2012; (c) June 10-15, 2012.

acted as the sole factor behind the lowest concentrations of ozone for the case of Mobile + Bio during the nighttime period (12:00 am - 6:00 am). Moreover, no 
significant difference has been observed between the ozone concentrations due to Area + Bio and Biogenic during the nighttime at this site. The relative contribution of individual source combinations at the three sites, over the study period June 1-15, are presented in Figures 4-6 for Sugarland, Bayland Park and Conroe respectively. At all three sites, biogenic sources influence the background ozone levels significantly, due to the isoprene emissions from vegetation in this region [11]. On the weekends, the contribution of Mobile sources toward ozone concentrations, is dominant only at the Conroe site, whereas both Point and Mobile Sources contribute to ozone at the other two sites. This pattern may be attributed to the continuous operation of refineries and other petrochemical point sources in the Greater Houston area, and the improvement in emissions standards of commonly used passenger vehicles. At all three sites, area sources are not a significant contributor to peak ozone levels, owing to their relatively low contribution in emission inventories of the HGB area [19]. Area sources only contribute to $7 \%$ of total $\mathrm{NO}_{\mathrm{x}}$ emissions in the $\mathrm{HGB}$ area in 2014, however, they are the leading contributor to VOC emissions (61\%). As most of the VOC emissions are to fugitive leaks of methane, and minimal amounts of HRVOCs, area sources don't impact the level of ozone at the three sites. This pattern suggests that further regulatory controls in the HGB area may focus more on mobile, rather than area sources.

Table 2 presents the averages of relative contribution of individual source categories at the three sites over the 15 day period. At the Sugarland site, biogenic sources contribute an average of $49.7 \% \pm 12.8 \%$ toward daily maximum ozone levels. The highest anthropogenic contributions occur from low-level point and mobile sources with $79.1 \% \pm 8.59 \%$ and $76.5 \% \pm 4.57 \%$ from Mobile + Bio and LPt + Bio combinations respectively. The location of the Sugarland site being in close proximity to U.S. Highway 59 and within 10 miles north of W.A. Parish power plant, the largest fossil-fuel power plant in Texas, is the principal reason for dominance of point and mobile sources contribution to ozone [12]. NOx and VOC emissions from highway traffic and the Parish power plant could have been the primary emission sources at the Site 1. Area sources don't contribute significantly to ozone at this Site. At the Bayland Park site, biogenic sources contribute an average of $43.1 \% \pm 12.0 \%$ toward peak ozone concentrations. The leading anthropogenic source category is mobile sources with $76.3 \% \pm 7.20 \%$ (Mobile + Bio case) and low-level point sources (LPt + Bio) with 71.6\% $\pm 6.01 \%$ contribution toward base-case daily maximum ozone concentrations. The Bayland park site is situated between U.S. Highway 59 and I-610 and is subject to a greater influence of mobile sources than point sources, in comparison to the Sugarland site. Both the Sites 1 and 2 have a high influence of isoprene emissions from biogenic sources that may be local or transported from the northeast region of Houston due to prevailing wind direction during the study period [11].

The contribution of biogenic sources is slightly lower at the Conroe site, with average contribution to base case, over the 15 days being $39.9 \% \pm 9.28 \%$. The 


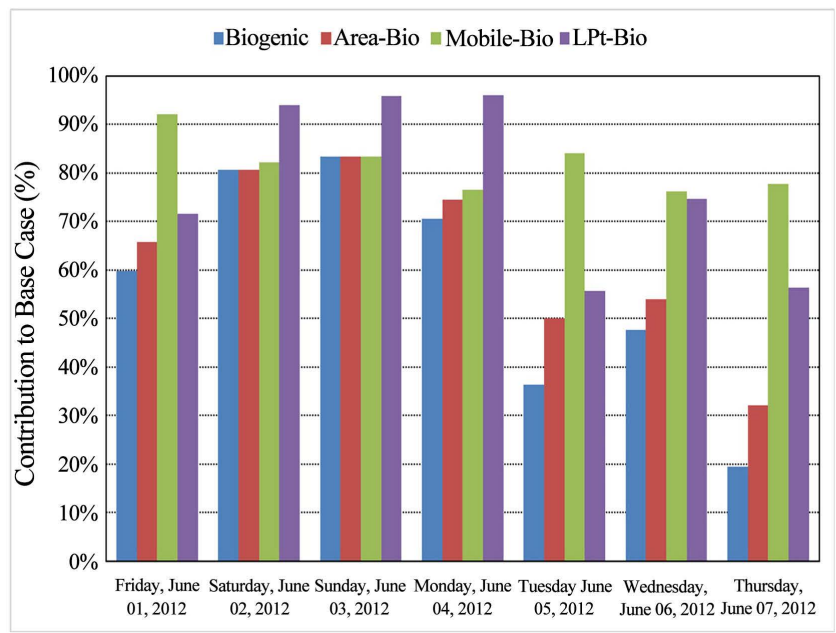

(a)

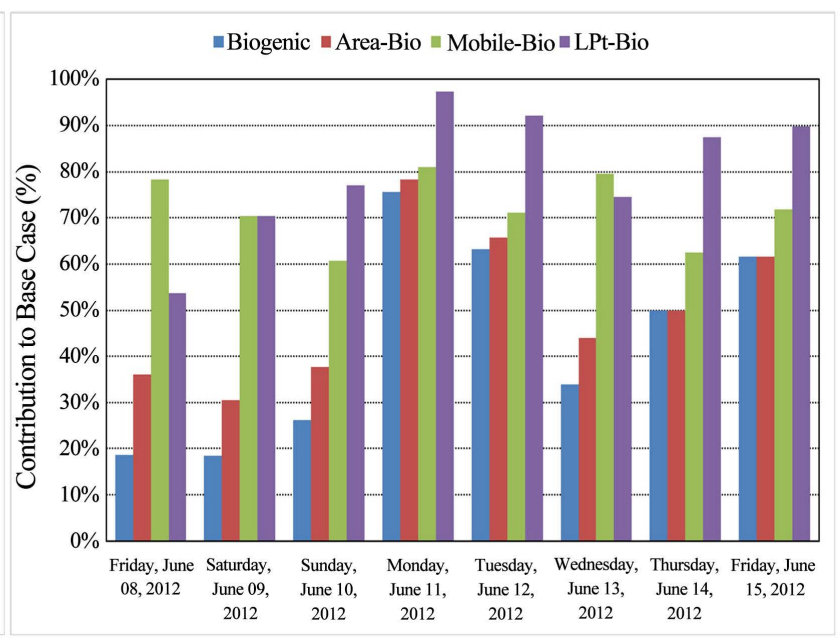

(b)

Figure 4. Contribution of different emission sources at Site 1 (UoH Sugarland) to daily maximum ozone concentration (a) June 1-7, 2012; (b) June 8-15, 2012.

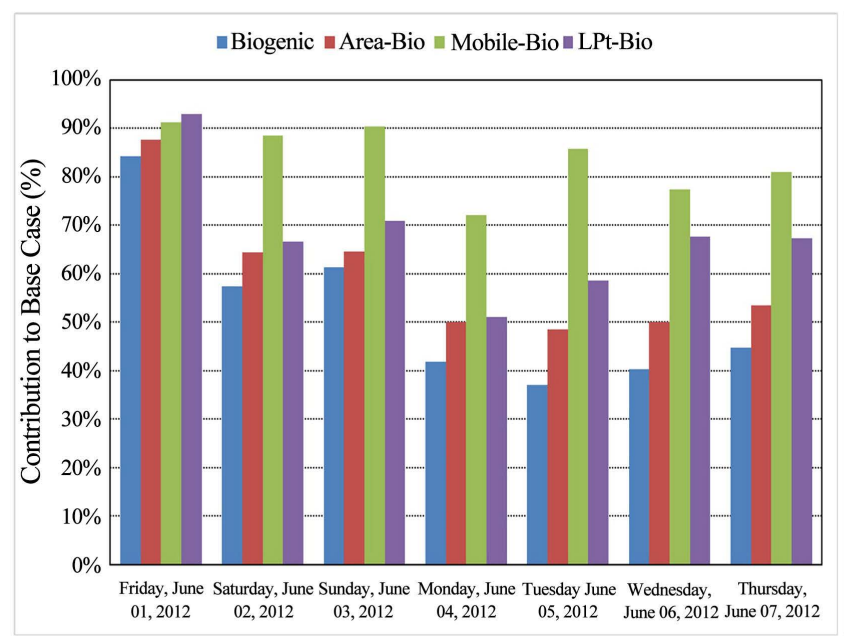

(a)

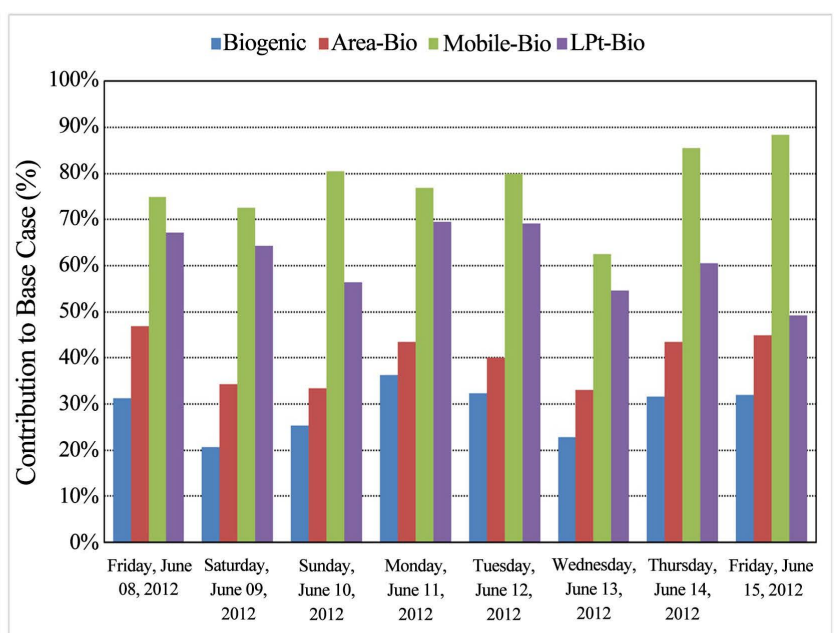

(b)

Figure 5. Contribution of different emission sources at Site 3 (Conroe), to daily maximum ozone concentration (a) June 1-7, 2012; (b) June 8-15, 2012.
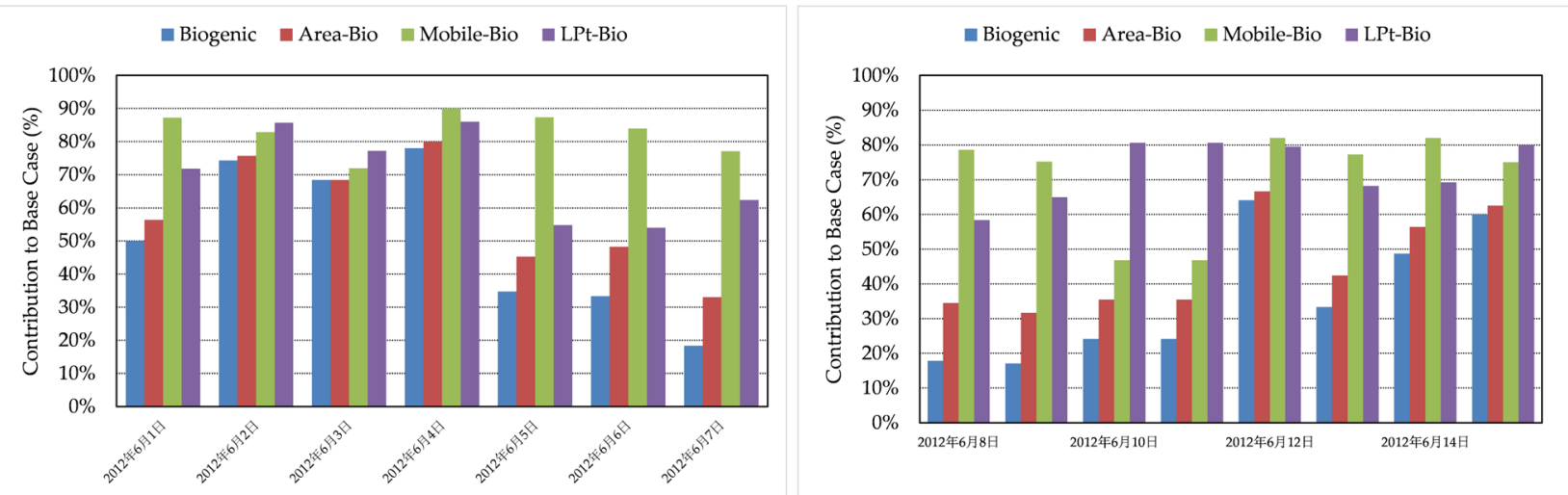

Figure 6. Contribution of different emission sources at Site 2 (Bayland Park), to daily maximum ozone concentration (a) June 1-7, 2012; (b) June 8-15, 2012. 
Table 2. 15-day averages of percentage relative contribution of different emission source categories to daily maximum ozone concentrations.

\begin{tabular}{ccccc}
\hline Site & Biogenic (\%) & Area + Biogenic (\%) & Mobile + Biogenic (\%) & LPt + Biogenic (\%) \\
\hline Site 1 & $49.7 \pm 12.8$ & $56.3 \pm 10.0$ & $76.5 \pm 4.57$ & $79.1 \pm 8.59$ \\
Site 2 & $43.1 \pm 12.0$ & $51.5 \pm 9.07$ & $76.3 \pm 7.20$ & $71.6 \pm 6.01$ \\
Site 3 & $39.9 \pm 9.28$ & $49.2 \pm 7.95$ & $80.5 \pm 4.44$ & $64.4 \pm 5.84$ \\
\hline
\end{tabular}

lower contribution of biogenic sources could be due to patterns in wind direction that influenced isoprene transport from the northeast Houston region during the study period [11]. In addition, Site 3 located in the northwest region could have lower background biogenic emissions. At site 3, mobile sources are the dominant source category, with $80.5 \% \pm 4.44 \%$ average contribution toward base-case ozone levels. The second and third important source combinations for ozone concentrations have been observed to be LPt + Bio and Area + Bio respectively. Overall it is indicated by this analysis that, in the study area which is within the HGB area, the occurrence of ozone exceedance is greatly affected by the mobile source categories which include onroad, offroad, and non-road vehicles. There is no significant difference identified between the Area + Bio and Biogenic cases for all three sites (Table 2), suggesting the weak influence of area sources for NOx and VOC precursors emissions in this region. Results from this study suggest that the focus of regulatory efforts in the HGB area may be more successful if targeting mobile source emissions. Specifically, since mobile sources contribute around $67 \%$ of total NOx emissions in the HGB area, and point sources only contribute $26 \%$, technology forcing regulations on NOx controls for onroad and offroad vehicles would likely yield optimum policy outcomes [19].

\section{Conclusions}

Ozone concentrations at three locations (Sugarland, Bayland Park and Conroe) in the HGB area have been simulated with CAMx photochemical model for the time period, June 1-15, 2012, and results were observed using the VERDI tool. For the study period, peak concentrations were observed to be spread out during the week at all three sites, indicating the weakening of the "ozone weekend effect" in the HGB area. Isoprene emissions in the region, and transport of biogenic VOCs from northeast Houston played a significant role at all three locations, as evidenced by an average contribution of $49.7 \% \pm 12.8 \%, 43.1 \% \pm 12.0 \%$, and $39.9 \% \pm 9.28 \%$ from biogenic sources toward daily maximum ozone concentrations, at Sugarland, Bayland Park and Conroe sites respectively. The relative contribution Mobile + Biogenic source category was the primary factor in this region, indicating the dominance of mobile source $\mathrm{NO}_{\mathrm{x}}$ emissions in determining peak ozone exceedances. Conroe site had lower deviations in the diurnal variations of ozone and lower peak concentrations as compared to Sugarland and Bayland park sites, due to the location being distant from the city center and the Houston ship channel. The remoteness of this site is also evidenced by the 
relatively lower contribution of $\mathrm{LPt}+$ Biogenic source category. The overall importance of emission source categories that need to be targeted for regulatory control in the HGB area were observed to be in the following sequence Mobile > Point $>$ Area sources.

\section{Acknowledgements}

This research is supported by the National Science Foundation (NSF) through the Center for Energy and Environmental Sustainability (CEES), an NSF CREST Center (Award \# 1036593). The technical content of this paper is solely the responsibility of the authors. The authors would like to acknowledge the contribution of Iqbal Hossan, a graduate student at Prairie View A \& M University, in assisting with CAMx runs.

\section{Conflicts of Interest}

The authors declare no conflicts of interest regarding the publication of this paper.

\section{References}

[1] TCEQ (2016) Houston-Galveston-Brazoria: Ozone History. https://www.tceq.texas.gov/airquality/sip/hgb/hgb-ozone-history

[2] Kleinman, L.I., Daum, P.H., Imre, D., Lee, Y.N., Nunnermacker, L.J., Springston, S.R., Weinstein-Lloyd, J. and Rudolph, J. (2002) Ozone Production Rate and Hydrocarbon Reactivity in 5 Urban Areas: A Cause of High Ozone Concentration in Houston. Geophysical Research Letters, 29, 105-1-105-4. https://doi.org/10.1029/2001GL014569

[3] Rappenglück, B., Perna, R., Zhong, S. and Morris, G.A. (2008) An Analysis of the Vertical Structure of the Atmosphere and the Upper-Level Meteorology and Their Impact on Surface Ozone Levels in Houston, Texas. Journal of Geophysical Research: Atmospheres, 113, No. D17. https://doi.org/10.1029/2007JD009745

[4] Reiss, R. (2006) Temporal Trends and Weekend-Weekday Differences for Benzene and 1,3-butadiene in Houston, Texas. Atmospheric Environment, 40, 4711-4724. https://doi.org/10.1016/j.atmosenv.2006.04.023

[5] Daum, P.H., Kleinman, L.I., Springston, S.R., Nunnermacker, L.J., Lee, Y.N., Weinstein-Lloyd, J., Zheng, J. and Berkowitz, C.M. (2004) Origin and Properties of Plumes of High Ozone Observed during the Texas 2000 Air Quality Study (TexAQS 2000). Journal of Geophysical Research: Atmospheres, 109, No. D17. https://doi.org/10.1029/2003JD004311

[6] Ryerson, T.B., Trainer, M., Angevine, W.M., Brock, C.A., Dissly, R.W., Fehsenfeld, F.C., Frost, G.J., Goldan, P.D., Holloway, J.S., Hübler, G., Jakoubek, R.O., Kuster, W.C., Neuman, J.A., Nicks, D.K., Parrish, D.D., Roberts, J.M., Sueper, D.T., Atlas, E.L., Donnelly, S.G., Flocke, F., Fried, A., Potter, W.T., Schauffler, S., Stroud, V., Weinheimer, A.J., Wert, B.P., Wiedinmyer, C., Alvarez, R.J., Banta, R.M., Darby, L.S. and Senff, C.J. (2003) Effect of Petrochemical Industrial Emissions of Reactive Alkenes and NOx on Tropospheric Ozone Formation in Houston, Texas. Journal of Geophysical Research: Atmospheres, 108, No. D8.

[7] Nielsen-Gammon, J.W., Tobin, J. and McNeel, A. (2005) A Conceptual Model for Eight-Hour Ozone Exceedances in Houston, Texas. Part I: Background Ozone 
Levels in Eastern Texas. HARC/TERC/TCEQ Report, p. 52.

[8] Nielsen-Gammon, J.W., Tobin, J. and McNeel, A. (2005) A Conceptual Model for Eight-Hour Ozone Exceedances in Houston, Texas. Part II: Eight-Hour Ozone Exceedances in the Houston-Galveston Metropolitan Area. HARC/TERC/TCEQ Report, p. 79.

[9] Murphy, C.F. and Allen, D.T. (2005) Hydrocarbon Emissions from Industrial Release Events in the Houston-Galveston Area and Their Impact on Ozone Formation. Atmospheric Environment, 39, 3785-3798. https://doi.org/10.1016/j.atmosenv.2005.02.051

[10] Kleinman, L.I., Daum, P.H., Imre, D., Lee, Y.N., Nunnermacker, L.J., Springston, S.R., Weinstein-Lloyd, J. and Rudolph, J. (2003) Correction to "Ozone Production Rate and Hydrocarbon Reactivity in 5 Urban Areas: A Cause of High Ozone Concentration in Houston". Geophysical Research Letters, 30, No. 12.

https://doi.org/10.1029/2003GL017485

[11] Li, G., Zhang, R., Fan, J. and Tie, X. (2007) Impacts of Biogenic Emissions on Photochemical Ozone Production in Houston, Texas. Journal of Geophysical Research: Atmospheres, 112, No. D10. https://doi.org/10.1029/2006JD007924

[12] Washenfelder, R.A., Trainer, M., Frost, G.J., Ryerson, T.B., Atlas, E.L., de Gouw, J.A., Flocke, F.M., Fried, A., Holloway, J.S., Parrish, D.D., Peischl, J., Richter, D., Schauffler, S.M., Walega, J.G., Warneke, C., Weibring, P. and Zheng, W. (2010) Characterization of $\mathrm{NOx}, \mathrm{SO}_{2}$, Ethene, and Propene from Industrial Emission Sources in Houston, Texas. Journal of Geophysical Research: Atmospheres, 115, No. D16. https://doi.org/10.1029/2009JD013645

[13] Shahriar, M.T., Kadiyala, A., Kommalapati, R. and Huque, Z. (2015) A Review of Ozone Studies in the Houston-Galveston-Brazoria Nonattainment Area, in Trace Materials in Air, Soil, and Water. American Chemical Society, Washington DC, 37-50. https://doi.org/10.1021/bk-2015-1210.ch002

[14] TCEQ (2017) Hourly Air Pollution Data by Day, Month, or Year. https://www.tceq.texas.gov/airquality/monops/hourly_data.html

[15] TCEQ (2016) Texas Air Quality Modeling_Files and Information (2012 Episodes). https://www.tceq.texas.gov/airquality/airmod/data/tx2012

[16] Marr, L.C. and Harley, R.A. (2002) Spectral Analysis of Weekday-Weekend Differences in Ambient Ozone, Nitrogen Oxide, and Non-Methane Hydrocarbon Time Series in California. Atmospheric Environment, 36, 2327-2335. https://doi.org/10.1016/S1352-2310(02)00188-7

[17] Shutters, S.T. and Balling, R.C. (2006) Weekly Periodicity of Environmental Variables in Phoenix, Arizona. Atmospheric Environment, 40, 304-310. https://doi.org/10.1016/j.atmosenv.2005.09.037

[18] Zhang, H. and Ying, Q. (2011) Contributions of Local and Regional Sources of NOx to Ozone Concentrations in Southeast Texas. Atmospheric Environment, 45, 2877-2887. https://doi.org/10.1016/j.atmosenv.2011.02.047

[19] TCEQ (2017) Texas Emission Sources-A Graphical Representation. https://www.tceq.texas.gov/airquality/areasource/texas-emissions-graphical-represe $\underline{\text { ntation }}$ 